NASA/TM-2003-212734

Evaluation of Candidate Materials for a High-Temperature Stirling Convertor Heater Head

Randy Bowman, Frank Ritzert, and Marc Freedman Glenn Research Center, Cleveland, Ohio 
Since its founding, NASA has been dedicated to the advancement of aeronautics and space science. The NASA Scientific and Technical Information (STI) Program Office plays a key part in helping NASA maintain this important role.

The NASA STI Program Office is operated by Langley Research Center, the Lead Center for NASA's scientific and technical information. The NASA STI Program Office provides access to the NASA STI Database, the largest collection of aeronautical and space science STI in the world. The Program Office is also NASA's institutional mechanism for disseminating the results of its research and development activities. These results are published by NASA in the NASA STI Report Series, which includes the following report types:

- $\quad$ TECHNICAL PUBLICATION. Reports of completed research or a major significant phase of research that present the results of NASA programs and include extensive data or theoretical analysis. Includes compilations of significant scientific and technical data and information deemed to be of continuing reference value. NASA's counterpart of peerreviewed formal professional papers but has less stringent limitations on manuscript length and extent of graphic presentations.

- TECHNICAL MEMORANDUM. Scientific and technical findings that are preliminary or of specialized interest, e.g., quick release reports, working papers, and bibliographies that contain minimal annotation. Does not contain extensive analysis.

- CONTRACTOR REPORT. Scientific and technical findings by NASA-sponsored contractors and grantees.
- CONFERENCE PUBLICATION. Collected papers from scientific and technical conferences, symposia, seminars, or other meetings sponsored or cosponsored by NASA.

- SPECIAL PUBLICATION. Scientific, technical, or historical information from NASA programs, projects, and missions, often concerned with subjects having substantial public interest.

- TECHNICAL TRANSLATION. Englishlanguage translations of foreign scientific and technical material pertinent to NASA's mission.

Specialized services that complement the STI Program Office's diverse offerings include creating custom thesauri, building customized databases, organizing and publishing research results ... even providing videos.

For more information about the NASA STI Program Office, see the following:

- Access the NASA STI Program Home Page at http://www.sti.nasa.gov

- E-mail your question via the Internet to help@sti.nasa.gov

- Fax your question to the NASA Access Help Desk at 301-621-0134

- Telephone the NASA Access Help Desk at 301-621-0390

- Write to:

NASA Access Help Desk

NASA Center for AeroSpace Information 7121 Standard Drive

Hanover, MD 21076 
NASA/TM-2003-212734

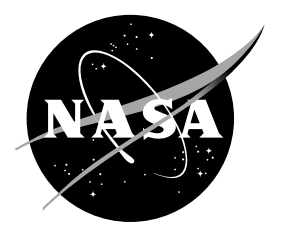

\section{Evaluation of Candidate Materials for a High-Temperature Stirling Convertor Heater Head}

Randy Bowman, Frank Ritzert, and Marc Freedman

Glenn Research Center, Cleveland, Ohio

Prepared for the

Space Technology and Applications International Forum (STAIF-2004)

sponsored by the American Institute of Physics

Albuquerque, New Mexico, February 8-12, 2004

National Aeronautics and

Space Administration

Glenn Research Center 


\section{Acknowledgments}

The authors gratefully acknowledge Gary Halford, NASA Glenn Research Center, for providing a fatigue analysis of the heater head.

This report is a formal draft or working paper, intended to solicit comments and ideas from a technical peer group.

This report contains preliminary findings, subject to revision as analysis proceeds.

This report is a preprint of a paper intended for presentation at a conference. Because of changes that may be made before formal publication, this preprint is made available with the understanding that it will not be cited or reproduced without the permission of the author.

Available from

NASA Center for Aerospace Information 7121 Standard Drive

Hanover, MD 21076
National Technical Information Service 5285 Port Royal Road Springfield, VA 22100 


\title{
Evaluation of Candidate Materials for a High-Temperature Stirling Convertor Heater Head
}

\author{
Randy Bowman, Frank Ritzert, and Marc Freedman \\ Materials Division, NASA Glenn Research Center, Cleveland, OH 44135 \\ (216) 433-3205; randy.r.bowman@nasa.gov
}

\begin{abstract}
The Department of Energy (DOE) and NASA have identified Stirling Radioisotope Generators (SRG) as a candidate power system for use on long-duration, deep-space science missions and Mars rovers. One of the developments planned for an upgraded version of the current SRG design is to achieve higher efficiency by increasing the overall operating temperature of the system. Currently, the SRG operates with a heater head temperature of $650{ }^{\circ} \mathrm{C}$ and is fabricated from the nickel base superalloy 718. This temperature is at the limit of Alloy 718's capability, and any planned increase in temperature will be contingent on identifying a more capable material from which to fabricate the heater head. To this end, an assessment of material candidates was performed assuming a range of heater head temperatures. The chosen alternative material candidates will be discussed, along with the development efforts needed to ensure that these materials can meet the demanding system requirements of long-duration operation in hostile environments.
\end{abstract}

\section{INTRODUCTION}

Under the auspices of NASA's Project Prometheus, the Nuclear Systems Program, the Department of Energy (DOE), Lockheed Martin, Stirling Technology Company (STC), and NASA Glenn Research Center (NASA GRC) are now developing a Stirling Radioisotope Generator (SRG) as a high-efficiency alternative to Radioisotope Thermoelectric Generators (RTG's) for possible use on future NASA space science missions. The SRG is being developed for multi-mission use (e.g., in environments with and without atmospheres), including providing electric power for unmanned Mars rovers and deep space missions. An attractive feature of the SRG system is that its efficiency of 20 to 25 percent would reduce the required amount of radioisotope by a factor of four or more compared to RTG's. This significantly reduces radioisotope cost, radiological payload, and system cost.

A follow-on task to this highly focused SRG flight program, is a NASA effort intended to develop an even higher efficiency, lower mass Stirling convertor for use with a radioisotope, reactor, or solar concentrator heat source. One of the goals for this upgraded version of the SRG is to achieve improved performance by increasing the Carnot efficiency of the convertor. To achieve this improvement, it is desirable to maximize the hot-end temperature. The current SRG heater head is made from the nickel base superalloy 718 and operates at $650{ }^{\circ} \mathrm{C}$, which is this alloy's maximum use-temperature. Further increases in temperature will require the use of more advanced high-temperature superalloys, ceramics, or refractory metal alloys. More advanced superalloys have the potential of increasing the operating temperature to perhaps $850^{\circ} \mathrm{C}$, while refractory materials (metals and ceramics) may allow temperatures to be as high as $1125^{\circ} \mathrm{C}$. As part of the overall advanced Stirling program, a materials assessment of potential hightemperature candidates was undertaken at NASA GRC. This report will summarize the findings to date.

\section{STIRLING ENGINE DESIGN AND REQUIREMENTS}

Current conventional design practices for these heater heads are based on the only generally accepted, hightemperature structural design code in the United States' public domain, ASME Code Case N-47. This code was developed for the design assessment of terrestrial-based nuclear power generation plants. The code addresses the 
following modes of failure: 1) creep rupture, 2) creep damage, 3) localized stresses, 4) reverse plasticity, 5) fatigue, creep-fatigue, and 6) creep ratcheting. The code recognizes only a limited number of superalloys (under several limited conditions i.e., heat treatment, thickness) that are currently used in the nuclear pressure vessel and piping industry. For various reasons, none of the Code Case N-47 alloys are candidates for use in the hot section of the Stirling power converter.

For the specific case of a deep-space Stirling Convertor, not all six of these failure modes will apply, and therefore will not impact the initial screening process. Specifically, for space-based applications it is envisioned that Stirling convertors will operate continuously once the radioisotope fuel has been loaded. The absence of repeated start-up and cool-down cycles greatly reduces the overall burden placed on the material system. In particular, because the reverse plasticity requirement is intended to insure that plasticity doesn't occur during shutdown, this material property criterion can be ignored during the screening process. Similarly, fatigue damage and creep-fatigue are also not considered significant since the internal gas pressure does not vary significantly and the resulting heater head wall stress will vary by only \pm 10 percent of the mean stress. Referring to a classical mean stress diagram (Modified Goodman, for example), and locating this service operational point on the normalized mean stress diagram, it is found to lie so far below the Modified Goodman boundary (which represents the lowest possible fatigue strength) that it is clear that fatigue is not an issue.

Therefore, for a continuously operating convertor, creep and creep-related mechanisms are the only dominant failure mechanisms, and thus was the mechanical property used to quickly screen a wide variety of materials. Of course, other factors in addition to failure mode considerations will also dictate whether a particular material is suitable for use as a heater head. The following is a generic list of screening criteria used to evaluate the candidate materials: 1) creep properties, 2) fabricability, 3) helium gas containment, 4) long-term stability/compatibility, 5) ability to form a hermetical close-out seal, and 6) ductility/toughness (to assist in fabrication, handling, and resistance to foreign object damage). In addition to these issues, each particular material system has its own unique characteristics that must be addressed as well. In the following sections, the selection criteria and subsequent choice of candidate materials for each class of material will be discussed.

\section{SUPERALLOYS FOR 650 TO $850{ }^{\circ} \mathrm{C}$ OPERATION}

For the lower end of the advanced heater head operating temperature range, superalloys are an obvious choice. Superalloys are successfully used at a higher proportion of their melting point than any other class of commercial metallurgical material. Although they are used in turbine engines at temperatures approaching $1150{ }^{\circ} \mathrm{C}$, the anticipated life of typical turbine components is on the order of 1000 hours for aircraft applications and perhaps 50,000 for land-based gas turbines. To achieve the desired lifetime of the Stirling convertor, namely 120,000 hrs, means that a reduction in the use-temperature will be necessary. Based on superalloy properties in general, a $120,000-\mathrm{hr}$ life roughly translates into a maximum use-temperature of about $850{ }^{\circ} \mathrm{C}$. Superalloys have a unique combination of high strength and high ductility. In addition, superalloys can be readily cast or mechanically worked, and are relatively easy to machine. Based on the six screening criteria listed above, it follows that this class of material will not be limited in terms of fabricability or ductility. As far as helium gas containment is concerned, the solubility of helium in metals is very low. In fact, it is generally assumed that inert gases are insoluble in metals with high melting temperatures and thus negligible helium loss would be expected. An analytical study was performed to verify this assumption and found that a loss of $25 \mathrm{~Pa}$ of helium gas loss is predicted to occur after 14 years of operation in an Alloy 718 Stirling heater head operating at $650^{\circ} \mathrm{C}$ and with a gas pressure of $2.6 \mathrm{MPa}$. Using the same analytical methods, the pressure loss at the higher temperature of $850{ }^{\circ} \mathrm{C}$ is predicted to be only $62 \mathrm{~Pa}$. Thus helium permeability is not considered to be a relevant criterion for screening superalloys. The remaining factors to be considered during screening are creep properties, hermetic sealing (joining issues), and stability.

\section{Long-Term Creep}

Creep rupture data for superalloys is readily available in the literature, although the vast majority of the data is for tests with a rupture life of less than 10,000 hours. To compare data reported for various stresses and temperatures, the literature data was normalized by using a Larson-Miller diagram (Larson, 1952). Larson-Miller plots were generated for practically all commercially available superalloys found in the literature. Accurately assessing the 
long-term creep properties of candidate materials for the heater head service conditions poses several challenges. The primary difficulty lies in the extremely long times involved - namely $120,000 \mathrm{hrs}$ ( $\sim 14$ years). Not surprisingly, very little creep data exists for such long times. This dictates that the creep response will, by necessity, be extrapolated from shorter-time tests. Even when ignoring for the moment the accuracy or appropriateness of a particular predictive creep model, caution must be used if creep data from the open literature is used as the input to the model. Creep response is highly dependent on composition, heat treatment, and grain size of the material. Another complication arises due to the fairly thin wall thickness of the heater head. It is well known that the creep properties of superalloys are dependent on the specimen thickness-to-grain size ratio. Since it is unlikely that thinsection 14-yr creep data will be available, it will be necessary to combine short and long-term data from the literature with short term-tests on the actual heater head material and rely on modeling to predict the viability of the material. So although the bulk of the creep database will be drawn from the literature and used to select the initial candidates, additional creep tests will be eventually required. The creep samples will need to have the identical thickness, heat treatment, and composition as the flight hardware so as to more accurately judge whether a particular material is appropriate for the mission profile.

\section{Microstructural Stability}

As superalloys become more highly alloyed to achieve the ever-increasing design requirements at higher temperatures, the issue of microstructural stability becomes increasingly important. Microstructural stability refers to the material's ability to retain its microstructure after prolonged exposure under stress at elevated temperature. Such a change in structure would result in concomitant change (normally a reduction) in the properties of the material in an undesirable or unpredictable manner. While instability is undesirable for overall performance, this effect also complicates the extrapolation of short-term data to long times. Most precipitation-hardened alloys exhibit some structural evolution with time. Although there are many solid-solution strengthened superalloys (such as Hastelloy X) that contain no $\gamma^{\prime}$ precipitates, and thus are very stable, the absence of $\gamma^{\prime}$ also means that these alloys do not have the required creep properties at high temperatures. Fortunately, the kinetics associated with any structural changes are very slow at the expected use-temperature for times less than $25,000 \mathrm{hrs}$. In the case of the Stirling heater head, although a maximum temperature of $850^{\circ} \mathrm{C}$ is not extreme in itself, the extremely long service life will tax the stability of these alloys. Therefore, when screening for potential alloys, high regard will be given to those alloys that were specifically designed to have a high degree of stability in addition to excellent creep properties.

Due to the relatively high vapor pressure of chromium (Cr), long-term exposure at elevated temperatures in the vacuum of space poses a risk of $\mathrm{Cr}$ loss in superalloys due to volatilization. Volatilization is especially important when the exposed surface area is high and the total volume of material is small, as is the case for the thin walls of the heater head. For these thin walls, even a small depletion layer can represent a large percentage of the total wall thickness. Assuming that the loss of $\mathrm{Cr}$ is a diffusion-controlled process, the $\mathrm{Cr}$ loss can be accurately predicted by solving Fick's diffusion law for the case of one-dimensional diffusion in a semi-infinite medium. When these calculations were performed, it was found that acceptably low $\mathrm{Cr}$ loss would occur for temperatures below $850{ }^{\circ} \mathrm{C}$.

\section{Weldability}

Most Stirling designs to date have used fusion-welding techniques (base metal is melted) to achieve the final hermetic closeout seal that contains the working gas in the heater head. Unfortunately, with the notable exception of Alloy 718, most high-strength (precipitation hardened) superalloys are difficult, if not impossible, to weld. The difficulty arises from cracks that develop in post weld thermal treatments; so-called strain-age cracks. Another problem is a loss of properties in the weld region. Tensile or yield properties aren't usually affected, but ductility is almost always reduced. The empirical parameter of $2 \mathrm{Al}+\mathrm{Ti}$ (where $\mathrm{Al}$ and $\mathrm{Ti}$ concentrations are in weight percent) has been found to be a good indicator of the weldability of an alloy. When $2 \mathrm{Al}+\mathrm{Ti}>6$, welding is considered to be difficult. Since the strength of superalloys is derived from the presence of the $\gamma^{\prime}$ precipitate, which has the composition of $\mathrm{Ni}_{3}(\mathrm{Al}+\mathrm{Ti}$ ), it is seen that higher strength alloys (high $\mathrm{Al}$ and $\mathrm{Ti}$ levels, and hence large volume fraction of $\left.\gamma^{\prime}\right)$, are the most difficult to weld. 
If solid-state techniques (techniques that don't melt the base alloy) can be used for hermetic sealing, the choice of candidate materials is less limited. Solid-state welding techniques such as friction, projection, and magnetic pulse welding, as well as brazing, transient liquid phase bonding, and diffusion bonding, are not susceptible to the difficulties associated with conventional welding and are being pursued in a parallel program. Therefore, although weldability is highly desirable, it is not a mandatory selection criterion.

\section{Candidate Superalloys}

Based on the criteria outlined above, five candidate superalloys where chosen. All of the candidate superalloys listed below have creep properties that are far superior to Alloy 718. In fact, most precipitation-hardened superalloys have creep properties that are superior to Alloy 718 at temperatures in excess of $650{ }^{\circ} \mathrm{C}$. The difficulty is finding alloys that have a balance of properties that meet the needs of the heater head. So while all the alloys chosen have superior creep properties to Alloy 718, they also have other issues that may prevent them from being successfully used as a heater head material. The following descriptions will emphasize the strengths and issues associated with each candidate replacement material. In general, cast alloys typically are capable of operating at higher temperatures and stresses than the wrought alloy counterparts. However, the higher strength of cast alloys comes at a price. As a class of material, cast superalloys tend to have less ductility and larger grains. The large grains are a handicap for the heater head application due to the thin walls. For specimens of a constant gage length and grain size, reducing the specimen thickness results in progressively shorter rupture lives and higher steady-state creep rates. The relative significance of this phenomenon to overall mechanical properties is dictated by the number of grains that are present through the thickness of the sample. This effect is of most concern in thin specimens where the thickness of the sample is on the same order of magnitude as the grain size.

\section{Udimet 720}

Udimet 720 is considered by many to be one of the most capable wrought superalloys. It can be fabricated for use at high temperature for either high tensile strength or high creep resistance. Unfortunately, the high creep resistance is obtained with a coarse grain structure, which may be a concern with the thin walls of the heater head as previously discussed. The chemical composition has been carefully balanced to provide structural and surface stability. After prolonged exposure at $845{ }^{\circ} \mathrm{C}$, U720 resists the deleterious microstructural changes that can adversely affect the ductility of other superalloys (Sczerzenie et al., 1988). The excellent balance of properties has been recognized in previous material selection activities for Space Stirling engines (Dhar, 1999). In this previous program, the formation of post-weld cracking could not be avoided in spite of intense effort to establish the correct welding parameters. Therefore, the current program will focus on exploring more advanced fusion techniques that have been developed in the intervening years, or non-fusion routes such as brazing, to accomplish the joining requirements.

IN738LC

IN738 is a cast nickel-base superalloy and is used extensively in gas turbine blades and vanes. It has excellent creep properties up to $980{ }^{\circ} \mathrm{C}$ and is microstructurally stable in terms of precipitation of unwanted phases. The only structural changes that have been reported consist of dissociation of MC carbides, formation of $\gamma^{\prime}$ grain boundary films, and growth of the $\gamma^{\prime}$ precipitates (Wlodek, 1999). Because of its tantalum and niobium content, the MC carbides do not dissociate to lower carbides and resultant grain boundary $\gamma^{\prime}$ films as rapidly as other cast alloys. Alloy 738LC, like other high-strength nickel-base superalloys, is not ordinarily considered weldable in the normal sense. If brazing is not feasible for achieving the hermetic seal, then less conventional, non-fusion techniques outlined previously will be required.

IN939

IN939 is also a cast nickel-base superalloy. It is widely used in its equiaxed grain condition as a vane in industrial gas turbines. IN939 has a weldability index factor of 7.5, which is one of the lowest factors (lower index numbers are easier to weld) of all cast alloys. Even though its index is low, it is still considered difficult to weld. CannonMuskegon has developed a modified version of IN939, designated CM 939 Weldable $^{\mathrm{TM}}$. Should it become necessary 
to fusion weld for hermetic sealing, this alloy may be a top candidate due to its combination of high creep strength and weldability.

\section{MarM-247}

MarM-247 is a cast superalloy, designed for use in the equiaxed grain condition, with a high volume fraction $(\sim 60 \%)$ of $\gamma$ 'and a high refractory element content $(\mathrm{Ta}+\mathrm{W}+\mathrm{Mo})$. It is intended for use at metal temperatures of about 980-1010 ${ }^{\circ} \mathrm{C}$. Of course, these use-temperatures are established assuming exposure times of 20,000 hrs or less. The long service life of the Stirling convertor will require a reduction in this maximum temperature by some, as yet unknown, amount. MarM-247 combines extremely high strength capabilities at elevated temperature with excellent castability. The alloy is an optimized version of MarM-246 and provides greater strength and stability at high temperature. The alloy does show a pronounced effect of specimen thickness on properties (Doner and Heckler, 2000) and it will be necessary to optimize the grain size for the eventual heater head wall thickness. MarM-247 has been widely used for almost 20 years, and as such has a fairly large database of properties available in the open literature.

\section{MA754}

MA754 is a mechanically alloyed nickel-base superalloy that is strengthened at high temperature by the presence of an ultrafine dispersed yttrium oxide $\left(\mathrm{Y}_{2} \mathrm{O}_{3}\right)$ phase in the matrix. MA754 is one of the most creep-resistant commercially available alloys for service over $1095^{\circ} \mathrm{C}$. At these temperatures, conventional superalloys can have a significant loss in properties as the $\gamma^{\prime}$-strengthening phase becomes unstable. The alloy has been successfully joined by laser and electron beam welding and by diffusion bonding. Brazing has also been used with great success for years in applications such as gas turbine engines. The excellent mechanical properties of MA754 are obtained by thermomechanical processing of the alloy to produce a stable, recrystallized grain structure that is coarse and highly elongated (Howson, Stulga, and Tien, 1980). Unfortunately, both of these characteristics are undesirable for the heater head. The coarse structure will impact properties due to the small thickness of the walls, and the highly directional mechanical properties will be inappropriate for the heater head that has a biaxial stress state. Although MA754 is a high-risk candidate because of its reliance on a highly elongated structure, the extreme stability of the alloy warrants exploration into its use in the heater head. Trials will be initiated to determine if a microstructure can be generated that provides sufficient mechanical properties for the current, low-stress, long-time, application.

\section{MATERIALS FOR $>850^{\circ} \mathrm{C}$ OPERATION}

For temperatures above $850^{\circ} \mathrm{C}$, superalloys are no longer an option due to strength and stability issues previously mentioned. For these temperatures, ceramic and refractory alloys are the primary candidates.

\section{Refractory Metal Alloys}

The definition of a refractory metal is not largely agreed upon within the materials community. The most widely accepted classification includes metals that have a melting temperature greater than $2000{ }^{\circ} \mathrm{C}$ and also have a bodycentered cubic (BCC) structure. However, such designations should not be relied upon as rigid since some metallic materials do not meet certain accepted definitions but still hold considerable promise for high-temperature, highstress space power application. Rhenium is one such example as its crystal structure is hexagonal close-packed (HCP) as opposed to BCC. Metallic elements that meet the $2000{ }^{\circ} \mathrm{C}$ melting temperature criteria include hafnium (Hf), niobium (Nb), iridium (Ir), ruthenium (Ru), molybdenum (Mo), tantalum (Ta), osmium (Os), rhenium (Re), and tungsten (W). Chromium (Cr) and rhodium (Rh) are only narrowly excluded. A significant amount of refractory metal/alloy development was accomplished during the SP100 program and preference was given to the alloys based on $\mathrm{Mo}, \mathrm{Nb}, \mathrm{Ta}$, and $\mathrm{W}$. Most of the other candidates were not considered to any large extent due to their limited availability and high cost. Regardless of reason, databases of Ir, Ru, and Os are small or non-existent and any consideration of alloys based on these metallic elements would come at a very high cost in both time and dollars. 
Of specific interest are the alloys that have ductile-to-brittle transition temperatures (DBTT) that are less than room temperature in both pre- and post-welded condition. Other primary design criteria include a design stress most likely not to exceed $138 \mathrm{MPa}$, favorable joining characteristics, long-term thermal stability, and good physical properties. Such targets exceed current heater head design requirements and would take advantage of the strong performance of refractory alloys at high temperatures and stresses. For screening purposes, a widely accepted mechanical property design criteria is the time to 1 percent creep strain at given temperature and stress levels. The most promising candidates will also probably have a pronounced existence in the literature.

\section{Refractory Metal Candidates}

Molybdenum and Mo alloys would be attractive for high-temperature application if it were not for their high DBTTs (above room temperature) in both the pre- and post-weld condition. Molybdenum alloys such as TZM perform very well in wrought form with respect to mechanical property design criteria. Molybdenum also could provide a weight advantage over other refractory metal counterparts due to its lower density. Alloying with Re improves the joining characteristics of Mo, however, not remarkably so, and it comes at the expense of mechanical properties. Molybdenum alloys only maintain their strength in wrought form, and recrystallization during processing would limit their effectiveness. Therefore, Mo alloys have high risk and were not considered as promising candidates. This decision was essentially based on the lack of confidence that Mo and Mo alloys could reliably maintain both their strength and non-brittle characteristics in the post-welded condition.

Alloys based on $\mathrm{Nb}$ have been widely considered for high-temperature space applications because of their good weldability and fabricability. Commercial alloy $\mathrm{Nb}-1 \mathrm{Zr}$ has been particularly considered as a promising candidate and has been very well characterized in the literature. This alloy is at a disadvantage for consideration as a refractory alloy since it has only moderate creep strength at higher temperatures. The best creep performance of $\mathrm{Nb}-1 \mathrm{Zr}$ is at temperatures where advanced nickel-base superalloys can be successfully applied as well. A potential advantage of $\mathrm{Nb}-1 \mathrm{Zr}$ over its superalloy counterparts is stability for long times at application temperatures. A second generation $\mathrm{Nb}-1 \mathrm{Zr}$ alloy (PWC-11) was developed by adding carbon to promote the formation of carbides for strengthening. Although $\mathrm{PWC}-11$ is stronger than its $\mathrm{Nb}-1 \mathrm{Zr}$ predecessor, it does not have an extensive manufacturing and property database. It is thus concluded that niobium alloys have modest promise for nextgeneration, high-temperature refractory alloy applications due to their marginal strength advantage at lower temperatures and stresses. Niobium alloys may be considered as an alternative to nickel-base superalloy application in some unique circumstances, but only when a verifiable advantage can be distinguished.

The most promising refractory alloy candidates for high-temperature heater head application were based upon Ta and $\mathrm{W}$. Tantalum alloys are highly developed and have continued to evolve over time (Ta-10W, T-111, and T-222) to ASTAR-811C. ASTAR-811C is promising for high-temperature application due to its high melting temperature, high strength, good weldability and fabricability, and ductility at low temperatures. ASTAR-811C derives its strength from both solid solution and dispersed phase strengthening. One potential drawback to consider with ASTAR-811C is that the alloy is highly affected by processing. Particular attention will be paid to controlling this factor. ASTAR-1211C and ASTAR-1511C are potentially even stronger alloys but are significantly less mature and were therefore not considered. At the highest temperatures considered for metallic application, W alloys deserve investigation as possible successors of the ASTAR family. At present, the extremely limited data on creep of W-25Re prevent reliance on extrapolation of its creep to 10 years' duration, but additional investigation of $\mathrm{W}$ alloys is still warranted. Unfortunately, W alloys are similar to Mo-based alloys with respect to high DBTTs and difficulty in welding.

The inclusion of Re as a refractory metal candidate for high-temperature space power application is due to its excellent high-temperature strength and low-temperature ductility. It also has good weldability and fabricability. The Re database is significantly underdeveloped due to historical cost and availability issues and the Re application to potential Stirling heater head application should automatically be considered as high-risk. This high risk, however, could have a tremendous upside.

ASTAR-811C and Re were chosen for in-depth study for the advanced Stirling heater head program. W-Re alloys could provide a worthwhile second-tier study along with, possibly, the Nb-based alloys. Long-term creep testing of all alloys is required and their ductility or brittleness after welding must be investigated. Other aspects such as weldability, microstructural stability, and environmental issues will also be addressed. The results of all refractory 
alloy research will provide space power system designers with information and options for future applications supporting ambitious space-related missions.

\section{Ceramics}

There are many non-metallic systems that can provide respectable mechanical properties at very high temperatures. Examples of non-metallics include carbides, nitrides, borides, oxides, intermetallics, silicides, sulphides, and silicates (Fleischer, 1985). In particular, ceramic materials (compounds containing metallic and non-metallic elements) offer a number of significant advantages over conventional metals and superalloys for the Stirling engine heater head application. In general, they have higher temperature capability, are more creep resistant and have a wider range of thermal conductivities. Conversely, there are also several concerns with ceramics in this application. They include a lower coefficient of thermal expansion (CTE) than the materials to which they will be attached, higher helium permeability, and higher manufacturing costs. A combination of improved design and careful choice of ceramic materials should be able to maximize the advantages and minimize the effects of the disadvantages.

A basic ceramic heater head design is shown in figure 1. It is composed of 4 elements that could be combined or eliminated depending upon the requirements, material properties or manufacturing priorities.

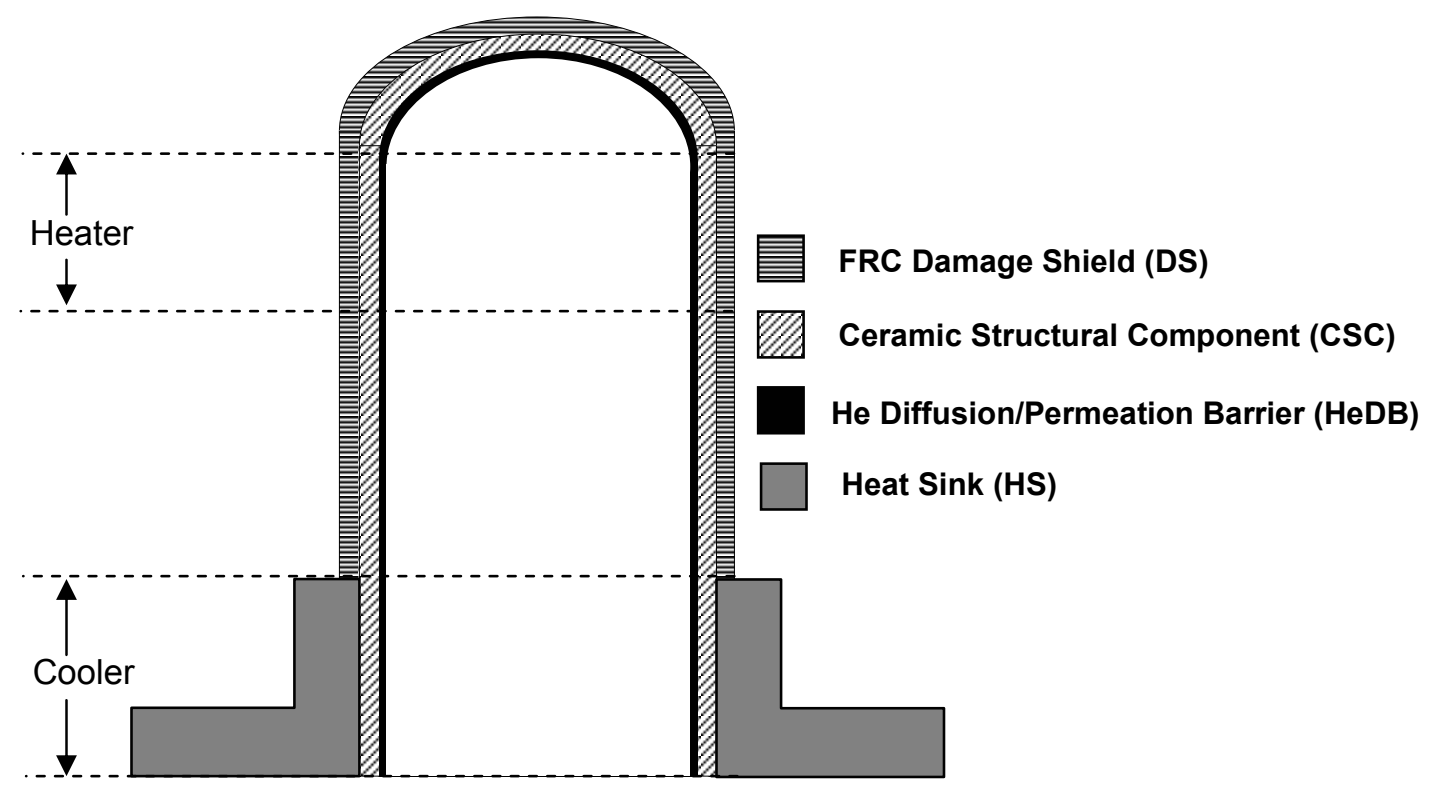

FIGURE 1.-Basic Ceramic Heater Head Design Elements.

The 4 elements are the damage shield (DS) that protects the structure during handling and use, the ceramic structural component (CSC) that provides both structural integrity and continuity throughout the structure, the $\mathrm{He}$ diffusion/permeation barrier that minimizes He permeation, if required, and the heat sink (HS) helps remove heat from the gas in the "cooler."

The damage shield is included to provide damage tolerance only. He permeability is not an issue. Thus, a ceramic matrix composite $(\mathrm{CMC})$ is proposed to provide both high strength and high toughness to the structure. The fiber reinforcement will be designed to provide high radial thermal conductivity in the "heater" and "cooler" region of the head and low axial thermal conductivity in the region between them. The initial material choice is a high density chemical vapor infiltration/melt infiltration $\mathrm{SiC} / \mathrm{SiC}$ or $\mathrm{C} / \mathrm{SiC}$ material with a braided fiber preform. The high density is especially important in the regions that require high thermal conductivity. Also, the CMC should have a good CTE match with the ceramic structural component (CSC). 
The CSC is the main load-bearing component of the heater head, as shown in figure 1. It must be chemically compatible with the DS and have similar CTE due to their close contact. The CSC can be either a separate component or a continuous part of the DS. Like the DS, it should have high radial thermal conductivity, but low axial conductivity. In this case, He permeability should be low, but, as discussed later, it is not a critical attribute. The initial material choice for the CSC is a fully dense monolithic SiC either continuous with or bonded to the DS. A second choice would be a monolithic silicon nitride. It may be easier in the latter case to control the microstructure to obtain the differential (radial vs. axial) thermal conductivity goals.

The helium diffusion/permeation barrier is envisioned as a non-structural component. It is only required if the CSC does not meet the low He permeability goal. It must be thermal expansion matched to the CSC, impermeable to He, and compatible with the braze/joint composition. This barrier can be a metal or metal coating, but initially, a silica coating on the CVI SiC CSC will be investigated.

The heat sink (HS), as shown in figure 1, is a non-structural component. It must be CTE matched to the CSC, have high thermal conductivity, and be compatible with the braze/joint composition. The first choice for this component will be fully dense CVI SiC continuous with or bonded to the CSC (same material as the CSC). This material has a higher thermal conductivity than any of the proposed metal alternatives. An alternate material would be an oriented $\mathrm{C} / \mathrm{C}$ composite with high radial thermal conductivity.

The challenges to this approach are threefold. First, very little is known about the He permeability of ceramics and CMCs. Initial studies will evaluate the proposed materials and guide the final component design. Second, the ceramic-metal joint must be hermetic and long lived. Although brazes and joints between some of the proposed materials have been demonstrated, much work must be done to both develop the specific compositions required for this application (material dependent and materials not yet selected) and evaluate the strength and life of the chosen braze/joint. Finally, assembly and testing of the heater head will need to be investigated.

\section{CONCLUSIONS}

Given the design requirements of an advanced Stirling heater head, namely 120,000 -hr life and greater than $650{ }^{\circ} \mathrm{C}$ metal temperature, several superalloy, refractory alloy, and ceramic material candidates have been identified based on literature data. Samples of each these materials will be obtained and further evaluated to determine their viability. For superalloys and refractory alloys, long-term creep and joining will be of particular interest. The main concerns to be addressed for ceramic materials are helium permeability and damage tolerance.

\section{REFERENCES}

Dhar, M., "Stirling Space Engine Program,” NASA/CR-1999-209164, Vol. 2, 1999.

Doner, M. and Heckler, J.A, "Identification of Mechanisms Responsible for Degradation in Thin-Wall Stress-Rupture Properties," in Superalloys 1988, edited by S. Reichman et al., The Metallurgical Society, Warrendale Pennsylvania, 2000, pp. 653-662.

Fleischer, R.L., "High-Temperature, High-Strength Materials-An Overview," Journal of Metals, 37, 16-20 (1985).

Howson, T.E., Stulga, J.E., and Tien, J.K., Metallurgical Transactions, 11A, 1599-1607 (1980).

Larson, F.R. and Miller, J., Trans. ASME, 74, 765-775 (1952).

Sczerzenie, F.E., Mancuso, S.O., Keefe, P.W., Maurer, G.E., and Boesch, W.J., "UDIMET 720,” Special Metals TR-88-002, 1988.

Wlodek, S.T., "The Stability of Superalloys," in Long Term Stability of High Temperature Materials, edited by G.E. Fuchs et al., The Minerals, Metals \& Materials Society, Warrendale, Pennsylvania, 1999, pp. 3-40. 
Public reporting burden for this collection of information is estimated to average 1 hour per response, including the time for reviewing instructions, searching existing data sources, gathering and maintaining the data needed, and completing and reviewing the collection of information. Send comments regarding this burden estimate or any other aspect of this collection of information, including suggestions for reducing this burden, to Washington Headquarters Services, Directorate for Information Operations and Reports, 1215 Jefferson Davis Highway, Suite 1204, Arlington, VA 22202-4302, and to the Office of Management and Budget, Paperwork Reduction Project (0704-0188), Washington, DC 20503.

\begin{tabular}{|l|l|l}
\hline 1. AGENCY USE ONLY (Leave blank) & $\begin{array}{c}\text { 2. REPORT DATE } \\
\text { December } 2003\end{array}$ & $\begin{array}{r}\text { 3. REPORT TYPE AND DATES COVERED } \\
\text { Technical Memorandum }\end{array}$ \\
\hline
\end{tabular}

4. TITLE AND SUBTITLE 5. FUNDING NUMBERS

Evaluation of Candidate Materials for a High-Temperature Stirling Convertor Heater Head

6. AUTHOR(S)

WBS-22-319-20-R1

Randy Bowman, Frank Ritzert, and Marc Freedman

7. PERFORMING ORGANIZATION NAME(S) AND ADDRESS(ES)

National Aeronautics and Space Administration

John H. Glenn Research Center at Lewis Field

Cleveland, Ohio 44135-3191

8. PERFORMING ORGANIZATION REPORT NUMBER

E-14259

9. SPONSORING/MONITORING AGENCY NAME(S) AND ADDRESS(ES)

10. SPONSORING/MONITORING AGENCY REPORT NUMBER

National Aeronautics and Space Administration

Washington, DC 20546-0001

NASA TM-2003-212734

\section{SUPPLEMENTARY NOTES}

Prepared for the Space Technology and Applications International Forum (STAIF-2004) sponsored by the American Institute of Physics, Albuquerque, New Mexico, February 8-12, 2004. Responsible person, Randy Bowman, organization code 5120, 216-433-3205.

12a. DISTRIBUTION/AVAILABILITY STATEMENT

12b. DISTRIBUTION CODE

Unclassified - Unlimited

Subject Category: 26

Distribution: Nonstandard

Available electronically at http://gltrs.grc.nasa.gov

This publication is available from the NASA Center for AeroSpace Information, 301-621-0390.

13. ABSTRACT (Maximum 200 words)

The Department of Energy (DOE) and NASA have identified Stirling Radioisotope Generators (SRG) as a candidate power system for use on long-duration, deep-space science missions and Mars rovers. One of the developments planned for an upgraded version of the current SRG design is to achieve higher efficiency by increasing the overall operating temperature of the system. Currently, the SRG operates with a heater head temperature of $650{ }^{\circ} \mathrm{C}$ and is fabricated from the nickel base superalloy 718. This temperature is at the limit of Alloy 718's capability, and any planned increase in temperature will be contingent on identifying a more capable material from which to fabricate the heater head. To this end, an assessment of material candidates was performed assuming a range of heater head temperatures. The chosen alternative material candidates will be discussed, along with the development efforts needed to ensure that these materials can meet the demanding system requirements of long-duration operation in hostile environments.

\section{SUBJECT TERMS}

Electric power; Power converters; Heat resistant alloys; Stirling engines 15. NUMBER OF PAGES 14

\begin{tabular}{|c|c|c|}
\hline $\begin{array}{c}\text { 17. SECURITY CLASSIFICATION } \\
\text { OF REPORT }\end{array}$ & $\begin{array}{c}\text { 18. SECURITY CLASSIFICATION } \\
\text { OF THIS PAGE } \\
\text { Unclassified }\end{array}$ & $\begin{array}{c}\text { 19. SECURITY CLASSIFICATION } \\
\text { OF ABSTRACT } \\
\text { Unclassified }\end{array}$ \\
\hline
\end{tabular}

